\title{
Influence of environment, morphology, and instrument size on lactating northern fur seal Callorhinus ursinus foraging behavior on the Lovushki Islands, Russia
}

\author{
John P. Skinner ${ }^{1, *}$, Vladimir N. Burkanov ${ }^{2}$, Russel D. Andrews ${ }^{1,3}$ \\ ${ }^{1}$ Alaska SeaLife Center, Seward, Alaska 99664, USA \\ ${ }^{2}$ National Marine Mammal Laboratory, Seattle, Washington 98115, USA, \\ and Kamchatka Branch of the Pacific Institute of Geography, Russian Academy of Sciences, Petropavlovsk-Kamchatsky \\ 683000, Russia \\ ${ }^{3}$ School of Fisheries and Ocean Sciences, University of Alaska Fairbanks, Fairbanks, Alaska 99775, USA
}

\begin{abstract}
Food limitation may be one of the causes of declines in northern fur seal populations on the Pribilof Islands. This hypothesis could be tested by comparing foraging behavior from decreasing Pribilof fur seal populations and an increasing population, such as on the Lovushki Islands, Russia, but factors other than prey availability that differ between sites may also influence behavior. Therefore, we evaluated such factors, including lunar cycle, weather, seal body size, and size of recording instruments, by studying 41 lactating northern fur seals on Lovushki Island over 4 summer breeding seasons using instrument packages of various sizes. With greater moonlight, seals increased foraging trip duration, dive depth, dive duration, and time spent on the bottom of dives but decreased descent rate and diving bout duration. Larger females made shorter shore visits, spent a greater proportion of time at sea diving, and had longer dive bouts than smaller females. Tags with larger frontal surface areas and higher drag caused seals to dive longer and to descend and ascend faster during dives but did not affect foraging trip durations or mass change rates. Seals, therefore, appeared capable of compensating for instrument effects on the scale of individual dives. Although lactating seals from Lovushki Island appeared to spend less foraging effort than seals from the Pribilofs, future studies should control for methodological factors and local environmental conditions before concluding whether food limitation could explain differences in population trajectories.
\end{abstract}

KEY WORDS: Pinniped · Diving behavior $\cdot$ Device effects $\cdot$ Lunar $\cdot$ Biotelemetry $\cdot$ Tags

\section{INTRODUCTION}

In the USA, the northern fur seal Callorhinus ursinus was listed as depleted under the Marine Mammal Protection Act in 1988. Since then, the fur seal population on the Pribilof Islands, home to $55 \%$ of the world's breeding population, has experienced an annual 5.8\% decline in pup production (Towell et al.
2006). Hypotheses about the reasons for this decline include predation, human interactions (e.g. by-catch, entanglement, ship disturbance, pollution), and food limitations, but the true causes remain unclear due to insufficient data on population vital rates, prey resources, and potential causes of mortality (NMFS 2007). At other rookeries, such as the Lovushki Island complex in Russia (Lovushki), a small rocky island 
group along the Kuril Island chain in the western Pacific Ocean (Fig. 1), fur seal populations have been growing. Northern fur seal pup production at Lovushki is currently increasing annually by $3.8 \%$ based on count surveys conducted in 1988, 2005, and 2006 (Burkanov et al. 2007). Although the factors potentially influencing these populations are difficult to study directly, they could be evaluated indirectly using fur seal foraging behavior as an indicator of prey availability (Boyd et al. 1994, Arnould et al. 1996, Costa 2007).

Lactating females of many fur seal species change their behavior in response to changes in their prey (Trillmich 1990). In years of reduced prey availability, Antarctic fur seals Arctocephalus gazella increased foraging trip duration (Costa et al. 1989). Seasonal declines in prey caused subantarctic fur seals A. tropicalis from Amsterdam Island to increase their proportion of time at sea spent diving and foraging trip duration (Beauplet et al. 2004). In contrast, northern fur seals increased their energy expenditure and increased their proportion of time at sea spent diving to maintain constant foraging trip durations during 2 different years with (presumably) contrasting prey availability (Costa \& Gentry 1986). These studies suggest that comparing the foraging behavior of lactating northern fur seals in the Pribilof population with the behavior of seals from a growing population, such as on Lovushki, may provide insight into whether food limitations are playing a role in the population declines. However, in making such a comparison, other factors that influence seal behavior and that could differ between sites need to be considered.

Environmental differences can have a profound influence on fur seal behavior: individuals modify their diving in association with factors such as location relative to the continental shelf edge (Goebel et al. 1991, Call et al. 2008), variability in ocean subsurface temperature stratification (Kuhn 2010), and presence of anticyclonic eddy edges (Sterling 2009). Northern fur seals are particularly responsive to changes in ambient light as they perform primarily uniform, epipelagic dives at night but will dive deeper along the ocean bottom during the day (Goebel et al. 1991). They also modulate their foraging depths with more subtle changes in ambient light: both adults and pups dive deeper in response

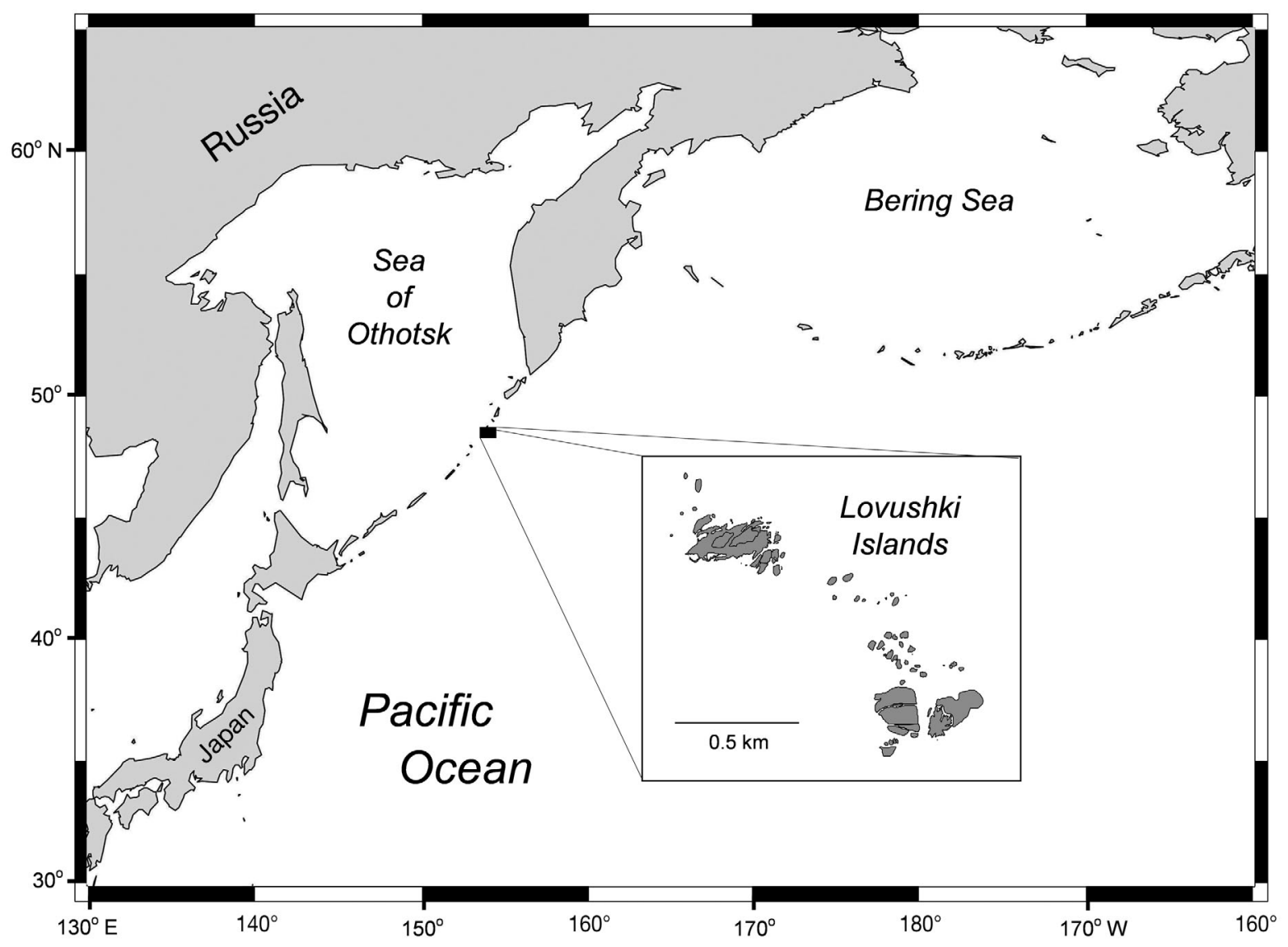

Fig. 1. Callorhinus ursinus. Study site located on the Lovushki Islands of the Kuril Island chain in the western Pacific Ocean 
to increased moonlight (Ream et al. 2005, Lea et al. 2010). These changes in behavior are likely due to seals tracking the distribution of their prey such as several species of squid (family Gonatidae) and deep-sea smelts (family Bathylagidae), which undergo daily vertical migrations (Croxall et al. 1985). The depths at which these prey are found at night are influenced by moonlight as they move deeper in response to increased ambient light (Boden \& Kampa 1967, Sinclair et al. 1994). Conditions that affect light attenuation, such as cloudiness and ocean turbidity, should also influence these vertical migrations, but these factors have not yet been examined. Although environmental factors are clearly important, inherent differences in behavior between individual seals may require equal consideration when studying behavior.

For diving mammals, body size is an important determinant of their breath-holding ability since larger animals have an increased aerobic dive capacity relative to their metabolic expenditure (Kooyman 1989, Schreer \& Kovacs 1997). Larger fur seals may behave differently than smaller individuals as a reflection of their ability to dive longer and deeper. Foraging tactics may also change with age as animals gain experience over time. This may explain why younger, smaller female northern fur seals made longer trips compared to larger, older individuals in the Pribilof Islands (Goebel 1988). Both mass and age also explained variation in Antarctic fur seal behavior (McDonald et al. 2009). Differences in behavior between individuals may also result from factors unrelated to a seal's innate attributes, such as the methods that are employed to observe foraging behavior itself (McMahon et al. 2011).

The impacts of animal handling are often difficult to evaluate, but some physical effects of instrument attachment are predictable. For example, tagging of marine mammals causes them to experience increased drag and, therefore, higher metabolic cost as they move through the water (Costa \& Gentry 1986, Costa 1988). Antarctic fur seals increased their foraging trip duration with instrument attachment (Boyd et al. 1991, 1997, Walker \& Boveng 1995, McCafferty et al. 1998). Boyd et al. (1997) compared behavior of lactating Antarctic fur seals when foraging with and without the attachment of a wood block. Seals with increased drag maintained a slower mean swim speed and decreased the duration and depth of their dives. These findings emphasize that comparisons of foraging behavior between fur seals should be careful to account for potential differences caused by the effect of instrumentation.
In this study, we set out to determine the relative influence of factors such as weather, moonlight, seal body size, and instrument size on lactating female northern fur seal foraging behavior. We measured seal behavior during 4 breeding seasons using several different instrument types of various sizes. We hypothesized that some behaviors often considered sensitive indices of prey availability would also vary with factors not directly related to prey, including the size of the monitoring instruments. Because our results showed that some variations in individual behaviors were not directly related to prey, we conclude that a more thorough examination of seal behavior across locations with differing population trends such as the Lovushki and Pribilof Islands is warranted. Future work should consider that differences in behavior across sites may be influenced by intrinsic and extrinsic factors that are not necessarily related to prey availability.

\section{MATERIALS AND METHODS}

\section{Capture, handling, and instrumentation}

Between June and August 2005-2008, 41 lactating northern fur seal females seen with their pups were captured on the Lovushki Islands of the Kuril Island chain in the western Pacific Ocean $\left(48.544^{\circ} \mathrm{N}\right.$, $153.674^{\circ} \mathrm{E}$ ). This sample size roughly represents $0.3 \%$ of the total lactating female population on Lovushki (Burkanov et al. 2007). Seals were captured and removed from the herd using a net or noose affixed to a long pole and immediately weighed to the nearest $0.1 \mathrm{~kg}$. In most cases, seals were transferred by skiff to a research vessel to minimize disturbance to other animals on the rookery. Seals were briefly restrained by hand until immobilized by general anesthesia using isoflurane gas (Heath et al. 1996). Standard length (SL) was recorded, and instruments were glued to the pelage on the head and/or on the dorsal region posterior to the scapulae with 5 Minute ${ }^{\circledR}$ Epoxy (Devcon). Seals were allowed to recover from anesthesia for $\geq 1 \mathrm{~h}$ prior to release. Seals were released by 2 methods: transportation back to their capture site or release from shipside $<1 \mathrm{~km}$ from their capture site. The majority of seals were released using the second method to further minimize disturbance to the rookery. We monitored the rookery to ensure that each seal returned to her pup and then completed $\geq 1$ foraging trip prior to recapture, reweighing, and instrument removal. Mass change rate (MCR) was calculated as the differ- 
ence between final and initial capture masses divided by the number of intervening days.

Twenty-one different instrument types were used in combination for the purposes of this and concurrent research. At a minimum, each northern fur seal was outfitted with a VHF radio transmitter (SirTrack) and one of either an Mk6, Mk9, Mk10, HyperMk10 (Wildlife Computers), or G5 (Fig. 2A; Cefas Technology) time-depth recorder (TDR). Other instruments included the Little Leonardo 3MPD3GT TDR (Fig. 2B), Crittercam $^{\text {TM }}$ Gen 5.7 camera/TDR (Fig. 2C; National Geographic Society), heart rate/stomach temperature recorder (HTR; Fig. 2B), and SPOT5 satellite tag (Wildlife Computers). Prototype devices built or modified at the Alaska SeaLife Center included a Hall-effect jaw position indicator magnet, mandible tri-axial acceleration sensor, and remote-release platform (Table 1). Some instruments were modified or glued together and deployed in combination to reduce drag (e.g. G5 TDR and VHF; Fig. 2A). Each

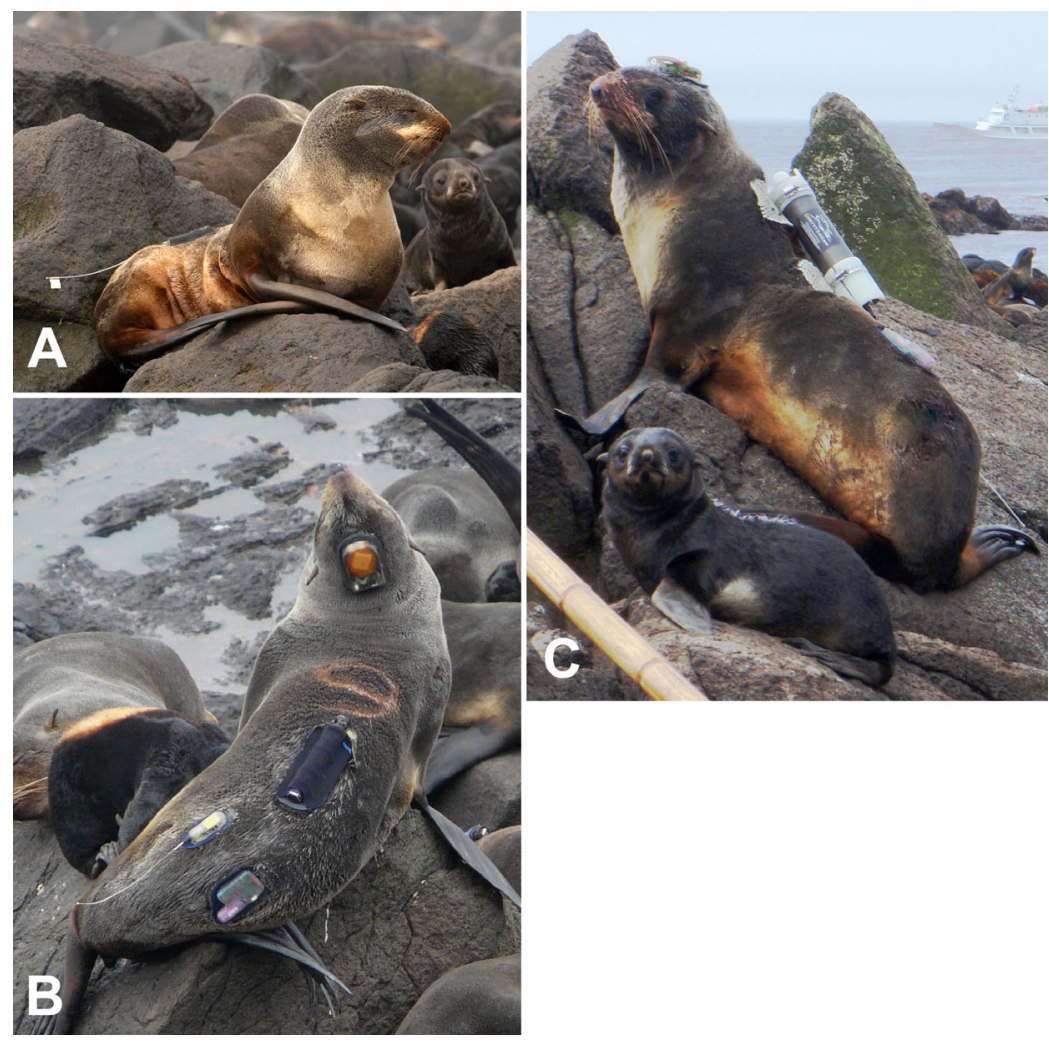

Fig. 2. Callorhinus ursinus. Three examples showing the arrangements of instruments attached to female northern fur seals. (A) CEFAS TDR and SirTrack VHF transmitter combination (lower right dorsal); combined frontal surface area $(\mathrm{cFSA})=5 \mathrm{~cm}^{2}$. (B) MK10-F (head), Little Leonardo TDR (mid-center dorsal), SirTrack VHF (lower left dorsal), and heart rate/stomach temperature recorder (HTR; lower right dorsal); $\mathrm{CFSA}=32 \mathrm{~cm}^{2}$. (C) MK10-F (head), CritterCam (mid-center), HTR (lower left dorsal), and SirTrack VHF (lower right dorsal; only antenna is visible); $\mathrm{cFSA}=64 \mathrm{~cm}^{2}$ instrument or glued combination was assigned an instrument identifier and was weighed and measured as it was configured for deployment (Table 1). For the complete set of instruments used during each deployment, we measured the combined instrument mass and combined frontal surface area (cFSA), the sum of exposed instrument surfaces orthogonal to the seal's direction of movement through the water (Table 2).

\section{Data collection and preparation}

TDRs recorded depth at rates of $0.33 \mathrm{~Hz}, 0.5 \mathrm{~Hz}$, $1 \mathrm{~Hz}$, or $2 \mathrm{~Hz}$ and in depth increments of $0.12 \mathrm{~m}$, $0.5 \mathrm{~m}$, or $2 \mathrm{~m}$ depending on the instrument type and programming. Depth records were subsampled to $0.33 \mathrm{~Hz}$. For cases when data were collected at $0.5 \mathrm{~Hz}$, values were interpolated between depth readings to allow subsampling at $0.33 \mathrm{~Hz}$. Temperature readings were recorded at least once every $5 \mathrm{~min}$, and all instruments except the G5 TDR recorded wet/dry status at $1 \mathrm{~Hz}$. Data recorded in the first $6 \mathrm{~h}$ following northern fur seal release and $1 \mathrm{~h}$ prior to recapture were excluded. To zero-offset correct the depth data, Visual Basic for Applications (Microsoft) was used to subtract the minimum depth from all depths found in a 20 min moving window. An additional $1 \mathrm{~m}$ was subtracted from all observations to ensure that all dive traces returned to the surface. Presence and absence data were collected in 2006-2008 in $30 \mathrm{~min}$ blocks by automated logging of VHF transmitter signals (ATS Model R4500S, Advanced Telemetry Systems). A single transmitter detection, which was defined as at least 2 pulses at the correct frequency and interpulse interval, within a 30 min block was taken to indicate that the seal was on or near the rookery.

\section{Seal behavior metrics}

To identify periods when northern fur seals were at sea, TDR data were plotted and inspected using graphing software (IGOR Pro, WaveMetrics). 
Table 1. Descriptions of individual or combined instruments according to how they were deployed on female northern fur seals during the study. Combined instruments are numbered in parentheses and separated by a semicolon. FSA: frontal surface area of individual or combined instrument(s) as oriented during deployment. ASLC: Alaska SeaLife Center; HTR: heart rate/ stomach temperature recorder

\begin{tabular}{|c|c|c|c|c|c|}
\hline Unit ID & Model & Manufacturer & No. used & Mass (g) & $\mathrm{FSA}\left(\mathrm{cm}^{2}\right)$ \\
\hline $\mathrm{A}$ & Crittercam & National Geographic & 2 & 770 & 36.0 \\
\hline $\mathrm{B}$ & (1) Mk6; (2) Remote release platform & (1) Wildlife Computers; (2) ASLC & 2 & 600 & 40.0 \\
\hline $\mathrm{C}$ & HyperMk10-FL & Wildlife Computers & 4 & 260 & 22.0 \\
\hline $\mathrm{D}$ & HyperMk10-F & Wildlife Computers & 11 & 205 & 20.0 \\
\hline $\mathrm{E}$ & Mk10-F & Wildlife Computers & 6 & 175 & 15.0 \\
\hline $\mathrm{F}$ & HyperMk10 & Wildlife Computers & 2 & 170 & 22.0 \\
\hline $\mathrm{G}$ & Mk10-AL & Wildlife Computers & 3 & 140 & 12.5 \\
\hline $\mathrm{H}$ & Mk10-L & Wildlife Computers & 2 & 135 & 12.0 \\
\hline $\mathrm{I}$ & HyperMk10 & Wildlife Computers & 5 & 130 & 8.0 \\
\hline $\mathrm{J}$ & 3MPD3GT & Little Leonardo & 9 & 120 & 5.0 \\
\hline $\mathrm{K}$ & SPOT5 & Wildlife Computers & 3 & 110 & 12.0 \\
\hline $\mathrm{L}$ & (1) Mk9; (2) HTR & $(1,2)$ Wildlife Computers & 2 & 95 & 8.5 \\
\hline $\mathrm{M}$ & HTR & Wildlife Computers & 4 & 80 & 8.0 \\
\hline $\mathrm{N}$ & HTR & Wildlife Computers & 8 & 60 & 5.5 \\
\hline $\mathrm{O}$ & (1) G5 TDR; (2) VHF & (1) CEFAS; (2) SirTrack & 6 & 55 & 7.0 \\
\hline $\mathrm{P}$ & (1) G5 TDR ; (2) VHF & (1) CEFAS; (2) SirTrack & 5 & 40 & 4.5 \\
\hline $\mathrm{Q}$ & (1) G5 TDR; (2) VHF & (1) CEFAS; (2) SirTrack & 5 & 35 & 3.0 \\
\hline $\mathrm{R}$ & VHF & SirTrack & 12 & 35 & 4.0 \\
\hline $\mathrm{S}$ & VHF & SirTrack & 13 & 30 & 3.0 \\
\hline $\mathrm{T}$ & Hall-effect jaw position magnet & ASLC & 4 & 25 & 1.5 \\
\hline $\mathrm{U}$ & Mandible tri-axial accelerometer & ASLC & 7 & 10 & 2.5 \\
\hline
\end{tabular}

The start and end of a foraging trip was defined as the first and last dive over any period of time when a seal remained in the water based on wet/dry sensor and temperature data. Only foraging trips $>6 \mathrm{~h}$ and shore visits between 2 consecutive, qualifying trips were included in analyses. VHF presence data were used to verify onshore visits when they were available. The package diveMove V0.9.8 (Luque 2007) was used with R software V2.11.0 (R Development Core Team 2010) to detect and calculate behavior metrics for each dive $\geq 2 \mathrm{~m}$. Phases of each dive including descent, bottom, and ascent were defined using the 'calibrateDepth' procedure with the following arguments: dive.thr $=2$, descent.crit. $q=0$, ascent.crit. $q=0$, and wiggle.tol $=0.5$. The dive.thr argument is the minimum depth threshold (in meters) to qualify as a dive. The descent.crit.q and ascent.crit.q arguments are the quantile thresholds used to determine the rate of descent below which the descent phase ends and the rate of ascent above which the ascent phase starts, respectively. The wiggle.tol argument sets the proportion of maximum dive depth above which wiggles are ignored and not allowed to influence the determination of the end of descent and below which wiggles are considered part of the bottom phase instead of the beginning of ascent (for further details refer to the diveMove manual $\mathbf{1}$ ). This procedure produced a summary of each dive including maximum depth (dive depth), duration, descent distance, descent time, time spent on the bottom of dive (bottom time), ascent distance, ascent time, and surface interval. Descent and ascent rates were calculated as respective distances divided by time. Proportion of time at sea spent diving was calculated as the sum of dive durations during each trip divided by the duration of the trip.

A bout-ending criterion was calculated for each seal using the methods of Sibly et al. (1990) as implemented by the procedure 'bouts2.nls' in diveMove. Five or more dives separated by surface intervals less than the bout-ending criterion were classified as occurring within a bout. Only dives within bouts were included in subsequent analyses. Response variables describing bout-level behavior for each seal were calculated as follows: bout duration, the period between first and last dive; and dive rate, the number of dives divided by the bout duration.

\section{Environmental variables}

Some of the instruments did not provide at-sea locations, so we were restricted to using environmen-

\footnotetext{
1 http://cran.r-project.org/src/contrib/Archive/diveMove/ diveMove_0.9.8.tar.gz
} 
Table 2. Callorhinus ursinus. Instrument deployment summary for female northern fur seals (n = 41). SL: standard length; MCR: mass change rate; cMass: combined instrument mass; cFSA: combined instrument frontal surface area; Unit ID: instruments attached during deployment (see Table 1 for descriptions); -: no data

\begin{tabular}{|c|c|c|c|c|c|c|c|c|c|c|c|}
\hline \multirow[t]{2}{*}{ Seal ID } & \multirow{2}{*}{$\begin{array}{c}\text { Deploy. } \\
\text { date }\end{array}$} & \multirow{2}{*}{$\begin{array}{l}\text { No. of } \\
\text { trips }\end{array}$} & \multirow{2}{*}{$\begin{array}{l}\text { TDR } \\
\text { record } \\
\text { length }(\mathrm{d})\end{array}$} & \multirow{2}{*}{$\begin{array}{l}\text { Trip } \\
\text { duration } \\
\text { (d) }\end{array}$} & \multirow{2}{*}{$\begin{array}{l}\text { Shore visit } \\
\text { duration } \\
\text { (d) }\end{array}$} & \multicolumn{3}{|c|}{- Biometrics -} & \multirow[b]{2}{*}{$\begin{array}{l}\text { cMass } \\
(\mathrm{g})\end{array}$} & \multicolumn{2}{|c|}{ Instruments } \\
\hline & & & & & & $\begin{array}{c}\text { Mass } \\
(\mathrm{kg})\end{array}$ & $\begin{array}{l}\mathrm{SL} \\
(\mathrm{cm})\end{array}$ & $\begin{array}{c}\mathrm{MCR} \\
\left(\mathrm{kg} \mathrm{d}^{-1}\right)\end{array}$ & & $\begin{array}{l}\text { CFSA } \\
\left(\mathrm{cm}^{2}\right)\end{array}$ & Unit ID \\
\hline 2005-05 & 09 Aug 05 & $2^{\mathrm{a}}$ & 4.9 & 1.5 & 0.9 & 50.3 & 140 & 0.22 & 740 & 55.0 & $\mathrm{~B}, \mathrm{~K}, \mathrm{~S}$ \\
\hline $2005-07$ & 10 Aug 05 & $2^{\mathrm{a}}$ & 4.5 & 1.5 & 1.0 & 42.5 & 133 & 0.02 & 235 & 23.5 & $\mathrm{~K}, \mathrm{~L}, \mathrm{~S}$ \\
\hline 2005-09 & 10 Aug 05 & $2^{\mathrm{a}}$ & 7.2 & 2.4 & 0.1 & 44.1 & 140 & 0.23 & 235 & 23.5 & $\mathrm{~K}, \mathrm{~L}, \mathrm{~S}$ \\
\hline $2005-10$ & 10 Aug 05 & $2^{\mathrm{a}}$ & 4.9 & 2.0 & 0.7 & 36.2 & 131 & -0.21 & 630 & 43.0 & $\mathrm{~B}, \mathrm{~S}$ \\
\hline 2006-12 & 11 Aug 06 & $1^{\mathrm{a}}$ & 5.3 & 3.4 & - & 31.7 & 119 & 0.12 & 440 & 35.0 & $\mathrm{D}, \mathrm{J}, \mathrm{N}, \mathrm{S}, \mathrm{T}$ \\
\hline 2006-13 & 11 Aug 06 & $1^{\mathrm{a}}$ & 4.2 & 3.3 & - & 44.9 & 140 & -0.05 & 440 & 35.0 & $\mathrm{D}, \mathrm{J}, \mathrm{N}, \mathrm{S}, \mathrm{T}$ \\
\hline 2006-14 & 11 Aug 06 & $3^{\mathrm{a}}$ & 7.9 & 1.7 & 0.8 & 29.7 & 121 & 0.33 & 415 & 33.5 & $\mathrm{D}, \mathrm{J}, \mathrm{N}, \mathrm{S}$ \\
\hline $2006-15$ & 12 Aug 06 & $2^{\mathrm{a}}$ & 5.2 & 1.2 & 0.4 & 42.0 & 128 & -0.19 & 490 & 40.0 & $\mathrm{D}, \mathrm{H}, \mathrm{J}, \mathrm{S}$ \\
\hline $2006-16$ & 12 Aug 06 & $1^{\mathrm{a}}$ & 2.0 & 0.6 & - & 42.7 & 132 & -0.10 & 490 & 52.0 & $\mathrm{D}, \mathrm{F}, \mathrm{N}, \mathrm{S}, \mathrm{T}$ \\
\hline 2006-19 & 13 Aug 06 & $1^{\mathrm{a}}$ & 6.5 & 5.5 & - & 36.5 & 129 & 0.73 & 565 & 58.5 & $\mathrm{D}, \mathrm{F}, \mathrm{H}, \mathrm{S}, \mathrm{T}$ \\
\hline 2006-21 & 13 Aug 06 & $5^{\mathrm{a}}$ & 22.0 & 1.8 & 0.9 & 37.7 & 120 & - & 35 & 3.0 & Q \\
\hline $2006-23$ & 13 Aug 06 & $7^{\mathrm{a}}$ & 22.0 & 1.0 & 0.9 & 40.5 & 127 & - & 35 & 3.0 & Q \\
\hline $2006-24$ & 14 Aug 06 & 1 & 18.4 & 4.5 & - & 38.6 & 131 & -0.48 & 35 & 3.0 & Q \\
\hline $2006-26$ & 14 Aug 06 & 5 & 18.5 & 1.7 & 1.0 & 45.5 & 128 & 0.14 & 35 & 3.0 & Q \\
\hline $2006-27$ & 14 Aug 06 & $7^{\mathrm{a}}$ & 22.0 & 1.3 & 0.9 & 34.7 & 122 & - & 35 & 3.0 & Q \\
\hline 2006-28 & 19 Aug 06 & 3 & 9.2 & 2.0 & 0.9 & 35.4 & 131 & 0.16 & 415 & 33.5 & $\mathrm{D}, \mathrm{J}, \mathrm{N}, \mathrm{S}$ \\
\hline 2006-29 & 19 Aug 06 & 2 & 8.9 & 3.2 & 0.4 & 36.9 & 128 & -0.47 & 415 & 33.5 & $\mathrm{D}, \mathrm{J}, \mathrm{N}, \mathrm{S}$ \\
\hline 2007-03 & 22 Jun 07 & 7 & 38.4 & 2.7 & 1.7 & 39.9 & 124 & -0.17 & 345 & 30.5 & $\mathrm{E}, \mathrm{G}, \mathrm{S}$ \\
\hline $2007-05$ & 22 Jun 07 & 9 & 43.2 & 2.3 & 1.9 & 40.0 & 132 & 0.93 & 350 & 31.5 & $E, G, R$ \\
\hline $2007-07$ & 22 Jun 07 & 21 & 35.0 & 0.6 & 0.6 & 51.9 & 136 & -0.04 & 40 & 4.5 & $\mathrm{P}$ \\
\hline 2007-08 & 22 Jun 07 & 6 & 35.0 & 3.5 & 1.7 & 36.8 & 123 & 0.08 & 40 & 4.5 & $\mathrm{P}$ \\
\hline 2007-18 & $28 \mathrm{Jul} 07$ & 1 & 6.7 & 3.3 & - & 39.9 & 131 & 0.07 & 40 & 4.5 & $\mathrm{P}$ \\
\hline 2007-19 & 29 Jul 07 & 1 & 6.1 & 1.6 & - & 41.2 & 127 & 0.05 & 40 & 4.5 & $\mathrm{P}$ \\
\hline $2007-20$ & 29 Jul 07 & 1 & 6.1 & 4.8 & - & 33.5 & 120 & 0.02 & 40 & 4.5 & $\mathrm{P}$ \\
\hline $2007-24$ & 29 Jul 07 & 1 & 5.8 & 5.0 & - & 33.2 & 126 & -0.08 & 440 & 40.0 & $\mathrm{D}, \mathrm{I}, \mathrm{N}, \mathrm{R}, \mathrm{U}$ \\
\hline $2007-25$ & $30 \mathrm{Jul} 07$ & 1 & 5.2 & 4.9 & - & 49.2 & 143 & 0.53 & 440 & 40.0 & $\mathrm{D}, \mathrm{I}, \mathrm{N}, \mathrm{R}, \mathrm{U}$ \\
\hline $2007-27$ & 31 Jul 07 & 1 & 5.9 & 3.8 & - & 39.4 & 132 & 1.31 & 390 & 39.0 & $\mathrm{D}, \mathrm{G}, \mathrm{R}, \mathrm{U}$ \\
\hline 2008-01 & 17 Jul 08 & 1 & 13.5 & 5.5 & - & 38.8 & 128 & -0.17 & 1060 & 63.0 & $A, E, M, R$ \\
\hline 2008-02 & 17 Jul 08 & 2 & 12.2 & 3.9 & 0.8 & 45.7 & 138 & -0.45 & 1075 & 64.5 & $A, C, R, U$ \\
\hline 2008-04 & $17 \mathrm{Jul} 08$ & 2 & 15.6 & 2.6 & 1.4 & 28.7 & 118 & -0.31 & 55 & 7.0 & $\mathrm{O}$ \\
\hline $2008-05$ & 17 Jul 08 & 1 & 13.2 & 5.3 & - & 30.2 & 109 & -0.18 & 55 & 7.0 & $\mathrm{O}$ \\
\hline 2008-06 & 17 Jul 08 & 2 & 13.7 & 3.7 & 3.6 & 43.6 & 127 & 0.11 & 55 & 7.0 & $\mathrm{O}$ \\
\hline 2008-11 & 17 Jul 08 & 2 & 13.7 & 4.3 & 1.7 & 38.4 & 132 & -0.25 & 55 & 7.0 & $\mathrm{O}$ \\
\hline 2008-07 & 18 Jul 08 & 3 & 10.7 & 2.4 & 1.5 & 30.7 & 122 & -0.19 & 410 & 32.0 & $\mathrm{E}, \mathrm{J}, \mathrm{M}, \mathrm{R}$ \\
\hline 2008-09 & 18 Jul 08 & 3 & 12.8 & 3.2 & 1.4 & 42.2 & 134 & -0.25 & 410 & 32.0 & $\mathrm{E}, \mathrm{J}, \mathrm{M}, \mathrm{R}$ \\
\hline 2008-10 & 18 Jul 08 & 6 & 10.9 & 1.0 & 0.9 & 44.0 & 129 & -0.75 & 410 & 32.0 & $\mathrm{E}, \mathrm{J}, \mathrm{M}, \mathrm{R}$ \\
\hline 2008-12 & 18 Jul 08 & 5 & 11.3 & 1.2 & 1.0 & 42.9 & 129 & - & 55 & 7.0 & $\mathrm{O}$ \\
\hline $2007-17$ & $20 \mathrm{Jul} 08$ & 3 & 9.0 & 2.1 & 0.9 & 45.5 & 134 & -0.21 & 55 & 7.0 & $\mathrm{O}$ \\
\hline 2008-13 & $20 \mathrm{Jul} 08$ & 2 & 13.3 & 4.7 & 2.1 & 32.4 & 125 & 0.07 & 435 & 36.5 & $\mathrm{C}, \mathrm{I}, \mathrm{R}, \mathrm{U}$ \\
\hline 2008-14 & 20 Jul 08 & 2 & 8.6 & 3.3 & 1.4 & 31.0 & 119 & -0.08 & 435 & 36.5 & C, I, R, U \\
\hline 2008-15 & $20 \mathrm{Jul} 08$ & 2 & 10.0 & 2.1 & 2.2 & 40.8 & 129 & -0.40 & 435 & 36.5 & $\mathrm{C}, \mathrm{I}, \mathrm{R}, \mathrm{U}$ \\
\hline
\end{tabular}

tal measures that would presumably not vary across the foraging range of our study animals. Values for lunar illumination fraction $(\mathrm{LIF} 0$ to 1 , full moon =1) and sun elevation angle were estimated hourly at the rookery location using published code (Austin et al. 1976). LIF describes the theoretical intensity of moonlight reaching the earth's surface in proportion to that of the full moon, when it is positioned directly overhead. Night was defined as periods of darkness when sun elevation was less than or equal to $-6^{\circ}$ (i.e. from evening to morning civil twilight). The vast majority of dives occurred at night (Fig. 3) and, therefore, dives during the day were excluded from all analyses. Hourly atmospheric pressure observations (ATM) for Severo-Kuril'sk, Russia (World Meteorological Organization Index \#32215, available at http:// meteo.infospace.ru/main.htm), located $290 \mathrm{~km}$ northeast of the rookery, were used to estimate the local 
weather conditions. We included ATM as a broad measure of atmospheric conditions. Low pressure is often associated with the formation of clouds in the Kuril Islands, which can significantly lower the amount of ambient light reaching the ocean surface. To match the scale of each analysis (see 'Statistical analyses'), environmental explanatory variables were summarized as the mean of values recorded (1) during an entire period of instrument deployment, (2) within each trip, and (3) at the start of each dive. Linear interpolation was used to estimate LIF and ATM at the time of each dive.

\section{Statistical analyses}

Explanatory variables were inspected using frequency distribution plots and were normalized by natural logarithm or square root transformations when necessary. An arcsine-square root transformation was applied to all values reported as proportions. Means are presented along with their standard error $( \pm \mathrm{SE})$. The effects of day of year, LIF, ATM, SL, and cFSA (explanatory variables) on seal mass change rate were examined using generalized linear models with an identity link. Linear mixed effects models (LME applied via package nlme V3.1-96; Pinheiro et al. 2011), including individual as the random effect, were used to measure the effect of explanatory variables on foraging trip duration, shore visit duration,

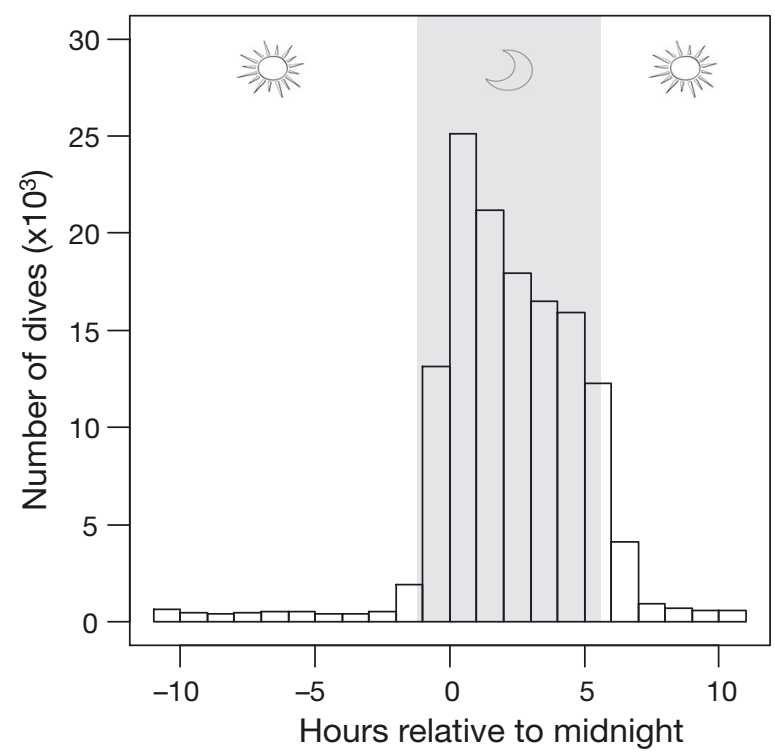

Fig. 3. Callorhinus ursinus. Distribution of all dives $\geq 2 \mathrm{~m}$ by hour of day relative to midnight $(n=135250)$. Grey area: period of darkness during which the sun was $>6^{\circ}$ below the horizon and proportion of time at sea spent diving, all on the scale of trips; and mean dive depth, dive duration, descent rate, bottom time, ascent rate, surface interval, dive rate, and bout duration on the scale of individual bouts. Dive depth was included as a covariate in models which contained dive duration, descent rate, bottom time, ascent rate, surface interval, dive rate, and bout duration as the response variable.

Each response variable was fit to a set of candidate models which included a random effects only (null) model, a global model (consisting of all explanatory variables), and a separate model for each combination of explanatory variables (main effects only). Akaike's second-order information criterion (AICc) was used to rank each model. Goodness-of-fit for the top-ranking (best) model was determined by inspection of residuals and quartile-quartile plots. Furthermore, the best model was evaluated against the random effects only (null) model by using a loglikelihood ratio test (McCullagh \& Nelder 1989). If the best model was found to be nonsignificant ( $\alpha=$ $0.05)$, this was taken to indicate that there were no reportable effects of the explanatory variables. If the residuals of the best model appeared heteroscedastic, all models were refit after log-transforming the response variable. Model-averaged parameter estimates $(\hat{\beta})$, unconditional standard errors for $\hat{\beta}$, unconditional confidence intervals, and relative importance values were calculated for each explanatory variable using AICc-weighted model averaging of all candidate models using methods of Burnham \& Anderson (2002) as implemented by R software package AICcmodavg V1.17 (Mazerolle 2011). Model averaging methods consider information about model uncertainty and therefore produce estimates that are less biased than those based on an individual model. Model $\hat{\beta}$ values provided the estimated slope of the relationship between response and explanatory variables. They were considered significant if their 95\% unconditional confidence interval did not include zero. Relative importance values provided an indication of how dominant each explanatory variable was in the top candidate models. The percent deviance explained (PDE) by fixed effect (i.e. all explanatory variables excluding individual effect) was calculated as:

$$
\mathrm{PDE}=1-\left(\frac{\operatorname{loglik}\left(\mathrm{LME}_{\mathrm{R}}\right)-\log \operatorname{lik}\left(\mathrm{LM}_{\phi}\right)}{\operatorname{loglik}\left(\mathrm{LME}_{\mathrm{R}+\mathrm{F}}\right)-\log \operatorname{lik}\left(\mathrm{LM}_{\phi}\right)}\right)
$$

where $\log \operatorname{lik}(X)$ is the estimate of the model likelihood for model $X, \mathrm{LME}_{\mathrm{R}}$ is a linear mixed effects model with random effects only, $\mathrm{LM}_{\phi}$ is a constant 
only linear model (no random or fixed effects), and $\mathrm{LME}_{\mathrm{R}+\mathrm{F}}$ is the best candidate model containing both random and fixed effects. PDE was used to estimate the contribution of the fixed effects relative to the total variance explained by the best model.

\section{RESULTS}

Instruments were deployed on dates ranging from 22 June to 19 August during the 4 year study (Table 2). In 2007-2008, deployments occurred over a greater span of dates and earlier in the season (22 June-31 July) compared to 2005-2006 (9-19 August). Across all years, mean lactating female mass and SL were $39.3 \pm 1.4 \mathrm{~kg}$ and $128 \pm 1.1 \mathrm{~cm}$, respectively. The mean MCR was $0.02 \pm 0.06 \mathrm{~kg} \mathrm{~d}^{-1}$ based on 37 seals (recapture masses were missing for 4 seals). Individual MCRs were highly variable and ranged from -0.75 to $1.31 \mathrm{~kg} \mathrm{~d}^{-1}$.

Presence and absence data from VHF transmitters were not collected in 2005 and were collected only intermittently during 2006. For 13 deployments, we could not use VHF data to verify when seals left or returned to the rookery (footnoted in Table 2). Mean foraging trip duration was $2.8 \pm 1.4 \mathrm{~d}(0.6-5.5 \mathrm{~d})$, and shore visit duration was $1.2 \pm 0.7 \mathrm{~d}(0.1-3.6 \mathrm{~d})$. The mean bout-ending criterion was $108 \pm 6.4 \mathrm{~s}$ (range, $36.9-217.3$ s) and mean bout duration was $46 \pm$ 2.9 min (range, 18-103 min). During 41 TDR deployments, 135250 dives were recorded. Based on the shape of the time-depth profile for these dives, seals mostly performed epipelagic dives. Infrequent benthic diving, as indicated by repeated U-shaped dives to uniform depths, occurred near the beginning and end of foraging trips. The grand mean percent of time seals spent diving while at sea was $15.1 \pm 1.0 \%$. Their maximum dive depth ranged from 32 to $105 \mathrm{~m}$ (mean, $67 \pm 2.9 \mathrm{~m}$ ), with only 2 seals making dives $>100 \mathrm{~m}$. The frequency distribution of dive depths during the night and day were similar, but seals conducted proportionally more dives to depths $>60 \mathrm{~m}$ during the day (Fig. 4). The frequency distribution for nighttime dives showed that seals were not focusing their diving effort at any particular depth as dives occurred at consistently decreased frequencies with increasing depth (Fig. 4A). Of the total recorded dives, $124643(92.2 \%)$ were at night (Fig. 3) and 120776 (89.3\%) occurred both at night and in bouts. The grand means for nighttime bout diving behaviors recorded for each seal during the first 4 foraging trips ( $\mathrm{n}=80503$ dives) are presented in Table 3.

Mass change rates were not influenced by any explanatory variables based on a lack of significance in model $\hat{\beta}$ values and the log-likelihood ratio test statistic $(p>0.05)$. Trip duration had a bimodal distribution (Fig. 5) which resulted in a poor model goodness-of-fit. This appeared to be caused by seals making 2 types of trips: overnight, which lasted $<1 \mathrm{~d}$ and occurred exclusively overnight; and extended, which lasted $\geq 1 \mathrm{~d}$ in duration. Among 41 individuals, 16 made $\geq 1$ overnight trip, while 40 made $\geq 1$ extended trip. There was likely a bias toward observing extended trips because seals were typically allowed to
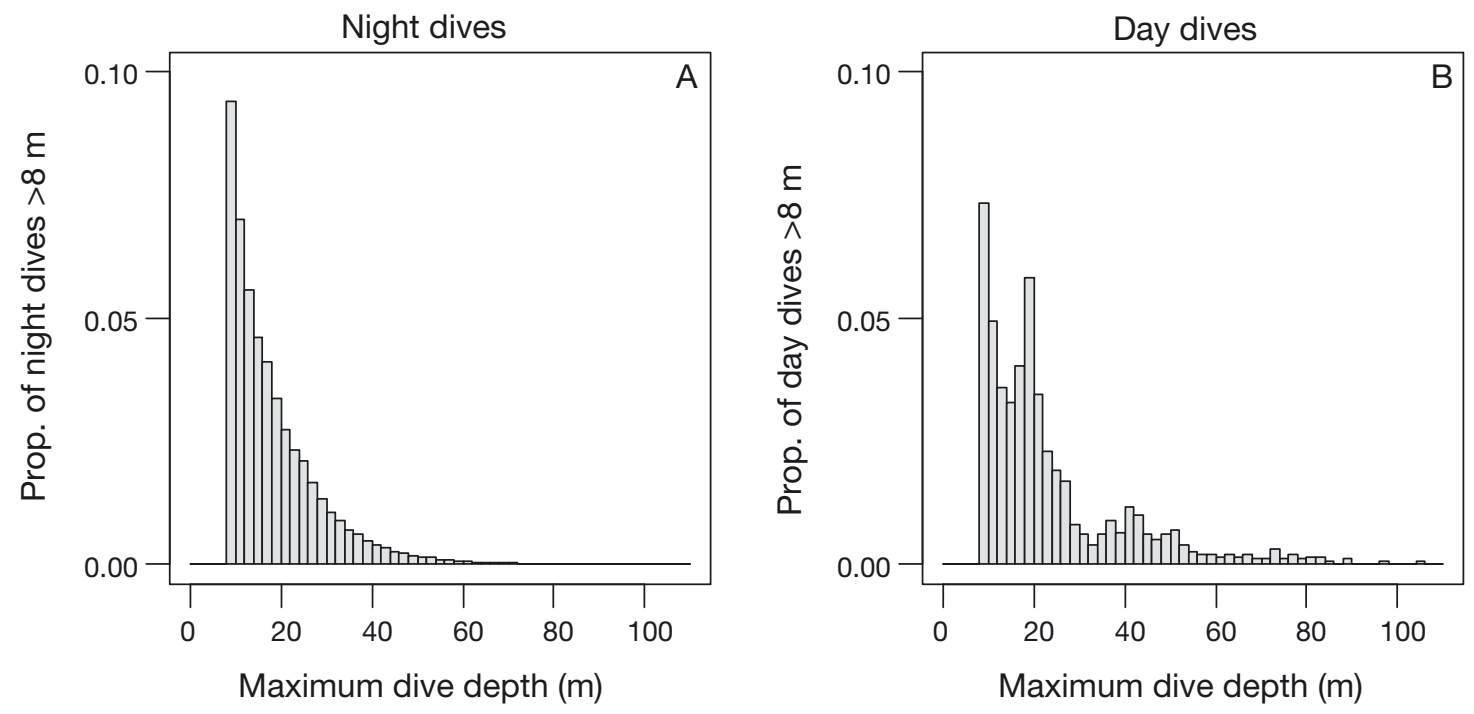

Fig. 4. Callorhinus ursinus. Frequency distribution of maximum depths of dives $>8 \mathrm{~m}$ recorded on female northern fur seals during $(\mathrm{A})$ nighttime $(\mathrm{n}=35000$ dives) and $(\mathrm{B})$ daytime $(\mathrm{n}=1003$ dives) 
Table 3. Callorhinus ursinus. Grand means and range of values for lactating northern fur seal foraging behavior $(\mathrm{n}=41)$ during 1 to 4 foraging trips. Summary includes dives $\geq 2 \mathrm{~m}$ that occurred in bouts at night

\begin{tabular}{|lcc|}
\hline Behavior & Mean $\pm \mathrm{SE}$ & Range \\
\hline Bout-ending criterion (s) & $108 \pm 6.4$ & $36.9-217.3$ \\
No. of bouts & $34 \pm 3.8$ & $2-93$ \\
Bout duration (min) & $45.5 \pm 2.9$ & $17.9-103.1$ \\
No. of dives & $1963 \pm 260$ & $130-7913$ \\
Maximum depth (m) & $11.6 \pm 0.9$ & $3.8-27.8$ \\
Dive duration (s) & $33.7 \pm 2.4$ & $12.8-93.6$ \\
Descent rate (m s & \\
Bottom time $(\mathrm{s})$ & $1.1 \pm 0.03$ & $0.77-1.67$ \\
Ascent rate $\left(\mathrm{m} \mathrm{s}^{-1}\right)$ & $14.8 \pm 1.3$ & $5.8-53.6$ \\
Surface interval $(\mathrm{s})$ & $1.08 \pm 0.03$ & $0.68-1.6$ \\
Dive frequency (dives $\mathrm{h}^{-1}$ ) & $19.1 \pm 1.3$ & $7.8-43$ \\
& $71.6 \pm 3.5$ & $26.1-127.4$ \\
\hline
\end{tabular}

make $\geq 1$ longer trip prior to recapture. Of the 28 seals that made $>1$ trip prior to recapture, $54 \%$ made at least 1 overnight trip, with some choosing to make overnight trips almost exclusively. For example, 20 out of 21 trips recorded for Seal 2007-07 were overnight. Data for overnight foraging trips and extended trips were subsequently modeled separately.

Durations for overnight trips increased with day of year (log-likelihood ratio test, $D=16.6, \mathrm{p}<0.01$ ). In contrast, extended trip durations were constant with day of year; however, they did increase during periods of higher LIF $(D=11.3, \mathrm{p}<0.01)$. Shore visit durations declined with respect to day of year and were negatively correlated with seal size $(D=11.7, \mathrm{p}<$ 0.01). Proportion of time seals dove at sea increased

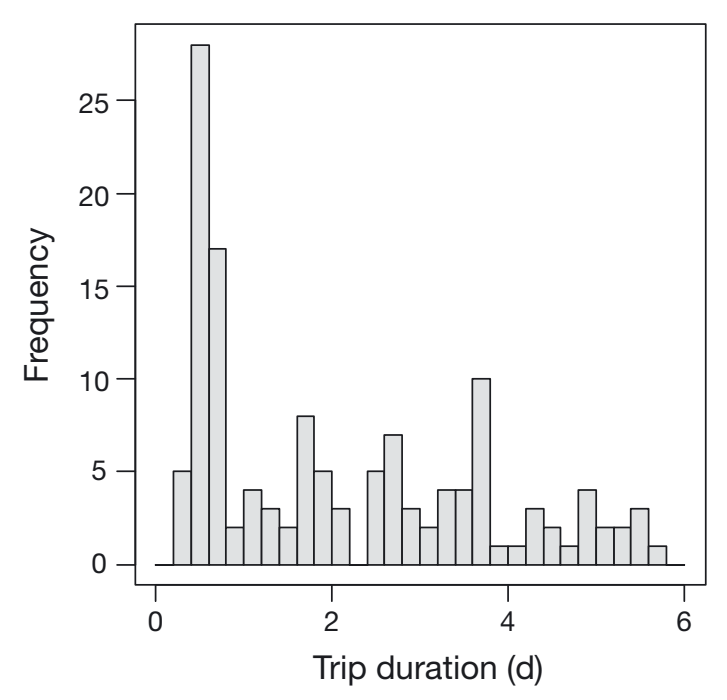

Fig. 5. Callorhinus ursinus. Frequency distribution of female northern fur seal foraging trip durations during the lactation period on Lovushki Islands with day of year and was positively correlated with their size $(D=26.3, \mathrm{p}<0.01)$. Dive depth also increased with day of year and showed a strong correlation with LIF $(D=50.6, \mathrm{p}<0.01)$. Dive duration was positively correlated with LIF, ATM, and dive depth but was negatively correlated with cFSA ( $D=$ $1690.2, \mathrm{p}<0.01$ ). Descent rate was negatively correlated with LIF and ATM but tended to increase with dive depth. Additionally, females increased their descent rate in response to higher $\mathrm{cFSA}(D=321.0$, $\mathrm{p}<0.01)$. Bottom time was positively correlated with LIF and dive depth $(D=803.5, \mathrm{p}<0.01)$. Ascent rate was negatively correlated with ATM but increased with cFSA and dive depth $(D=367.1$, $\mathrm{p}<0.01)$. Surface interval showed a positive correlation with LIF and dive depth $(D=55.4, \mathrm{p}<0.01)$. Both dive rate and bout duration were negatively correlated with LIF and positively correlated with dive depth $(D=728.3$, $\mathrm{p}<0.01$ and $D=223.4, \mathrm{p}<0.01$, respectively). Bouts also tended to be longer for larger females. Model averaging goodness-of-fit statistics for each response variable are presented in Table 4 . This table also shows the model-averaged parameter estimate $(\hat{\beta})$ and the $\hat{\beta}$ unconditional standard error for each explanatory variable. Relative importance values are presented in Table 5. Explanatory variables with a significant $\hat{\beta}$ (boldface in Table 5) tended to have a higher relative importance value $(\geq 0.75)$ compared to those with a nonsignificant $\hat{\beta}$ (range, $0.27-0.68$ ). To compare the effects of cFSA to those of LIF, model average $\hat{\beta}$ values were used to calculate the predicted values and $95 \%$ prediction intervals for behaviors significantly affected by LIF. The predicted percent change in dive duration and descent and ascent rates with a change in cFSA from 3 to $30 \mathrm{~cm}^{2}$ and a change in LIF from 0 to $25 \%$ are presented in Table 6.

\section{DISCUSSION}

Certain aspects of lactating female northern fur seal behavior on Lovushki appeared to be different than previously reported for females on the Pribilof Islands. Shore visit durations on Lovushki (1.2 d) were shorter than those on the Pribilof Islands (2.2 d; Gentry \& Holt 1986) and the range of values reported at other rookeries (range, 1.4-2.3 d; Gentry 1998). Foraging trips $(2.8$ d) were considerably shorter than those observed on the Pribilof Islands (range, 5.8-9.8 d) and were shorter than those on Medney Island $(3.5 \mathrm{~d})$, the rookery previously reported to have the shortest mean trip duration for 
Table 4. Callorhinus ursinus. Model-averaged parameter estimates $(\hat{\beta})$ and unconditional standard errors in parentheses, showing associations between lactating female behavior and covariates as measured using linear mixed effects models. Results are presented for candidate sets with a significant difference between best and null models (log-likelihood ratio test, $\alpha=0.05)$. n: number of seals included in the modeling; PDE: proportion of deviance explained by fixed effects; DOY: day of year; LIF: lunar illumination fraction (arcsin-sqrt, \%); ATM: atmospheric pressure (mbar); SL: animal standard length (sqrt, $\mathrm{cm})$; cFSA: combined tag frontal surface area $\left(\mathrm{cm}^{2}\right)$; DEP: mean dive depth (log, $\left.\mathrm{m}\right)$. -: not included in models. Level of significance is denoted as ${ }^{*}$ for $\mathrm{p}<0.05$ and ${ }^{* *}$ for $\mathrm{p}<0.01$

\begin{tabular}{|c|c|c|c|c|c|c|c|c|}
\hline \multirow[t]{2}{*}{ Behavior } & \multirow[t]{2}{*}{$\mathrm{n}$} & \multirow[t]{2}{*}{ PDE } & \multicolumn{4}{|c|}{$\hat{\beta}$ (unconditional SE) } & \multirow[b]{2}{*}{ cFSA } & \multirow[b]{2}{*}{ DEP } \\
\hline & & & DOY & LIF & ATM & $\mathrm{SL}$ & & \\
\hline Overnight trip duration (d) & 16 & 0.90 & $\begin{array}{l}0.0041^{* *} \\
(0.0010)\end{array}$ & $\begin{array}{l}-0.00373 \\
(0.15)\end{array}$ & $\begin{array}{c}-0.00463 \\
(0.0030)\end{array}$ & $\begin{array}{c}0.0466 \\
(0.081)\end{array}$ & $\begin{array}{c}-0.00175 \\
(0.0010)\end{array}$ & - \\
\hline Extended trip duration (d) & 40 & 0.91 & $\begin{array}{c}-0.0144 \\
(0.011)\end{array}$ & $\begin{array}{l}3.15^{* *} \\
(1.03)\end{array}$ & $\begin{array}{c}0.0052 \\
(0.037)\end{array}$ & $\begin{array}{c}-0.448 \\
(0.54)\end{array}$ & $\begin{array}{l}0.00676 \\
(0.0088)\end{array}$ & - \\
\hline Shore visit duration (log, d) & 28 & 0.56 & $\begin{array}{l}-0.018^{* *} \\
(0.006)\end{array}$ & $\begin{array}{c}0.63 \\
(0.82)\end{array}$ & $\begin{array}{l}0.02 \\
(0.017)\end{array}$ & $\begin{array}{r}-0.95^{*} \\
(0.39)\end{array}$ & $\begin{array}{c}0.0041 \\
(0.0062)\end{array}$ & - \\
\hline $\begin{array}{l}\text { Proportion of time at sea } \\
\text { spent diving (arcsin-sqrt, \%) }\end{array}$ & 41 & 0.72 & $\begin{array}{r}0.0035^{* *} \\
(0.00084)\end{array}$ & $\begin{array}{l}-0.12 \\
(0.075)\end{array}$ & $\begin{array}{c}-0.00084 \\
(0.0023)\end{array}$ & $\begin{array}{l}0.1^{*} \\
(0.045)\end{array}$ & $\begin{array}{l}-0.0012 \\
(0.00072)\end{array}$ & - \\
\hline Depth (log, m) & 41 & 0.09 & $\begin{array}{l}0.01^{* *} \\
(0.0034)\end{array}$ & $\begin{array}{r}1.1^{* *} \\
(0.18)\end{array}$ & $\begin{array}{c}-0.0093 \\
(0.0056)\end{array}$ & $\begin{array}{l}-0.3 \\
(0.31)\end{array}$ & $\begin{array}{c}0.0091 \\
(0.0049)\end{array}$ & - \\
\hline Dive duration $\left(\log _{1}, \mathrm{~s}\right)$ & 41 & 0.80 & $\begin{array}{c}0.0011 \\
(0.0014)\end{array}$ & $\begin{array}{r}0.52^{* *} \\
(0.085)\end{array}$ & $\begin{array}{l}0.0069^{* *} \\
(0.0026)\end{array}$ & $\begin{array}{c}-0.018 \\
(0.087)\end{array}$ & $\begin{array}{c}-0.0031^{*} \\
(0.0013)\end{array}$ & $\begin{array}{c}0.7^{* *} \\
(0.013)\end{array}$ \\
\hline Descent rate $\left(\mathrm{m} \mathrm{s}^{-1}\right)$ & 41 & 0.45 & $\begin{array}{l}-0.0022^{*} \\
(0.001)\end{array}$ & $\begin{array}{l}-0.4^{* *} \\
(0.059)\end{array}$ & $\begin{array}{r}-0.0044^{*} \\
(0.0017)\end{array}$ & $\begin{array}{l}0.15 \\
(0.084)\end{array}$ & $\begin{array}{c}0.0032^{*} \\
(0.0014)\end{array}$ & $\begin{array}{c}0.15^{* *} \\
(0.0083)\end{array}$ \\
\hline Bottom time $(\log , \mathrm{s})$ & 41 & 0.70 & $\begin{array}{l}-0.000095 \\
(0.0021)\end{array}$ & $\begin{array}{l}0.72^{* *} \\
(0.13)\end{array}$ & $\begin{array}{c}0.0076 \\
(0.004)\end{array}$ & $\begin{array}{c}0.06 \\
(0.13)\end{array}$ & $\begin{array}{c}-0.0025 \\
(0.0021)\end{array}$ & $\begin{array}{c}0.61^{* *} \\
(0.019)\end{array}$ \\
\hline Ascent rate $\left(\mathrm{m} \mathrm{s}^{-1}\right)$ & 41 & 0.41 & $\begin{array}{c}-0.0016 \\
(0.0011)\end{array}$ & $\begin{array}{c}-0.046 \\
(0.061)\end{array}$ & $\begin{array}{c}-0.0068^{* *} \\
(0.0018)\end{array}$ & $\begin{array}{c}0.051 \\
(0.089)\end{array}$ & $\begin{array}{c}0.0049^{* *} \\
(0.0014)\end{array}$ & $\begin{array}{c}0.17^{* *} \\
(0.0088)\end{array}$ \\
\hline Surface interval (log, s) & 41 & 0.19 & $\begin{array}{c}0.0027 \\
(0.0024)\end{array}$ & $\begin{array}{l}0.66^{* *} \\
(0.14)\end{array}$ & $\begin{array}{c}0.0006 \\
(0.0044)\end{array}$ & $\begin{array}{l}-0.26 \\
(0.15)\end{array}$ & $\begin{array}{l}-0.002 \\
(0.0027)\end{array}$ & $\begin{array}{c}0.1^{* *} \\
(0.021)\end{array}$ \\
\hline Dive rate $\left(\log , \mathrm{h}^{-1}\right)$ & 41 & 0.66 & $\begin{array}{c}-0.0016 \\
(0.0013)\end{array}$ & $\begin{array}{c}-0.5^{* *} \\
(0.081)\end{array}$ & $\begin{array}{c}-0.0042 \\
(0.0025)\end{array}$ & $\begin{array}{c}0.084 \\
(0.082)\end{array}$ & $\begin{array}{c}0.0019 \\
(0.0013)\end{array}$ & $\begin{array}{r}-0.34^{* *} \\
(0.012)\end{array}$ \\
\hline Bout duration (log, min) & 41 & 0.97 & $\begin{array}{c}-0.0026 \\
(0.0032)\end{array}$ & $\begin{array}{c}-1.2^{* *} \\
(0.23)\end{array}$ & $\begin{array}{l}-0.005 \\
(0.0073)\end{array}$ & $\begin{array}{c}0.34^{*} \\
(0.17)\end{array}$ & $\begin{array}{c}-0.0021 \\
(0.003)\end{array}$ & $\begin{array}{c}0.54^{* *} \\
(0.035)\end{array}$ \\
\hline
\end{tabular}

lactating northern fur seals (Gentry 1998). Shorter mean foraging trip durations on Lovushki may have been due to females choosing to make both overnight and extended foraging trips. Similar behavior was observed for seals arriving early in the breeding season at Kitovi rookery on St. Paul Island (Goebel 1988). There, it was thought that younger females were switching between short and long trips due to their inexperience. This behavior was also observed among Antarctic and subantarctic fur seals on Macquarie Island (Goldsworthy 1999) and among northern fur seals on Bogoslof Island, a relatively new breeding site along the Aleutian Islands in Alaska (Ream et al. 1999). The proximity of rookeries to deep pelagic water was thought to allow females to undertake relatively short foraging trips in those studies.

Lovushki females spent a smaller proportion of time diving while at sea than conspecifics from the Pribilof Islands (15\% cf. $28 \%$, respectively; Gentry et al. 1986). Additionally, mean diving depth by Lovushki females $(12 \mathrm{~m})$ was shallow compared to a mean depth of $62 \mathrm{~m}$ calculated for females on the Pribilof Islands using individual depths reported for shallow and deep divers (Goebel et al. 1991). Only 14 females and a total of 50 dives reached a depth $\geq 75 \mathrm{~m}$ on Lovushki (Fig. 4) in contrast to Pribilof females that commonly dove greater than this depth. These results provide evidence that Lovushki females are using foraging tactics that differ from those on the Pribilof Islands. To understand the reasons for these differences, a proper comparison should account for the potential influence of other factors on female diving behavior.

For 2 reasons, we chose to include depth as a covariate when modeling dive behavior. First, dive depth has been shown to explain changes in other aspects of dive behavior. The correlation coefficient between dive depth and dive duration was 0.81 for female northern fur seals on the Pribilof Islands 
Table 5. Callorhinus ursinus. Relative importance values describing the weighted occurrence of each explanatory variable in the candidate set of models. Bold values indicate that the corresponding parameter estimate $(\hat{\beta})$ was found to be significant $(\alpha=0.05)$, and + or - symbols indicate the sign of the association. Explanatory variable abbreviations as in Table 4. -: variable not included in candidate model set

\begin{tabular}{|lrrrrrr|}
\hline Behavior & DOY & LIF & ATM & SL & cFSA & DEP \\
\hline Overnight trip duration (+) $\mathbf{0 . 9 9}$ & 0.23 & 0.47 & 0.25 & 0.55 & - \\
Extended trip duration & 0.44 & $\mathbf{( + )} \mathbf{0 . 9 6}$ & 0.24 & 0.31 & 0.30 & - \\
Shore visit duration & $\mathbf{( - )} \mathbf{0 . 9 5}$ & 0.30 & 0.37 & $\mathbf{( - )} \mathbf{0 . 7 8}$ & 0.29 & - \\
$\begin{array}{l}\text { Proportion of time at } \\
\quad\end{array}$ & $\mathbf{( + )} \mathbf{1 . 0 0}$ & 0.52 & 0.27 & $\mathbf{( + )} \mathbf{0 . 7 8}$ & 0.55 & - \\
sea spent diving & & & & & & \\
Depth & $\mathbf{( + )} \mathbf{0 . 9 7}$ & $\mathbf{( + )} \mathbf{1 . 0 0}$ & 0.59 & 0.38 & 0.67 & - \\
Dive duration & 0.34 & $\mathbf{( + )} \mathbf{1 . 0 0}$ & $\mathbf{( + )} \mathbf{0 . 9 2}$ & 0.28 & $\mathbf{( - )} \mathbf{0 . 8 2}$ & $\mathbf{( + )} \mathbf{1 . 0 0}$ \\
Descent rate & $\mathbf{( - )} \mathbf{0 . 7 5}$ & $\mathbf{( - )} \mathbf{1 . 0 0}$ & $\mathbf{( - )} \mathbf{0 . 9 0}$ & 0.64 & $\mathbf{( + )} \mathbf{0 . 8 5}$ & $\mathbf{( + )} \mathbf{1 . 0 0}$ \\
Bottom time & 0.27 & $\mathbf{( + )} \mathbf{1 . 0 0}$ & 0.68 & 0.29 & 0.43 & $\mathbf{( + )} \mathbf{1 . 0 0}$ \\
Ascent rate & 0.53 & 0.33 & $\mathbf{( - )} \mathbf{1 . 0 0}$ & 0.30 & $\mathbf{( + )} \mathbf{0 . 9 9}$ & $\mathbf{( + )} \mathbf{1 . 0 0}$ \\
Surface interval & 0.38 & $\mathbf{( + )} \mathbf{1 . 0 0}$ & 0.27 & 0.57 & 0.33 & $\mathbf{( + )} \mathbf{1 . 0 0}$ \\
Dive rate & 0.41 & $\mathbf{( - )} \mathbf{1 . 0 0}$ & 0.61 & 0.38 & 0.49 & $\mathbf{( - )} \mathbf{1 . 0 0}$ \\
Bout duration & 0.33 & $\mathbf{( - )} \mathbf{1 . 0 0}$ & 0.32 & $\mathbf{( + )} \mathbf{0 . 7 2}$ & 0.33 & $\mathbf{( + )} \mathbf{1 . 0 0}$ \\
\hline
\end{tabular}

\section{Seasonal variation}

Significant day of year effects (Table 4) indicated that Lovushki females were increasing the duration of their overnight foraging trips and shortening their shore visits over the course of lactation. Other studies have shown a trend of increasing northern fur seal trip duration with time in lactation (Gentry et al. 1986, Loughlin et al. 1987). This has also been reported for Antarctic fur seals (McCafferty et al. 1998) and Australian fur seals Arctocephalus pusillus doriferus (Arnould \& Hindell 2001). Foraging activity of Lovushki females, as measured by proportion of time at sea spent diving, and diving depths also increased with day of year. These might

(Gentry et al. 1986). Here, we attempted to report the effects of explanatory variables independent of the intermediary influence of depth to simplify the interpretation of results. Second, associations between depth and other dive behaviors may describe the mechanisms by which seals respond to factors that change their foraging efficiency. For example, with deeper diving, Lovushki females increased their bottom time. They accomplished this by extending their overall dive duration and increasing their descent and ascent rates during deeper dives. These modifications to behavior during deeper dives seem to match with predictions of optimal foraging theory for diving animals (Houston \& Carbone 1992). Controlling for strong associations with depth provides an opportunity to examine more subtle changes in behavior due to other factors. have been explained by shifts in prey availability and distribution or the increasing energetic demands of pups throughout lactation. Furthermore, longer night length, with season, may have allowed females to increase their time spent foraging. However, this effect would not explain the association seen between dive depth and day of year. Within these broader temporal trends, we also found that behavior varied over shorter timescales in association with factors related to changing environmental conditions.

\section{Moonlight effects}

We examined the effect of LIF as a proxy for the amount of nighttime ambient light experienced by females while foraging. Moonlight was found to be

Table 6. Callorhinus ursinus. Estimated change in female northern fur seal dive duration and descent rates with increased combined tag frontal surface area (cFSA) from 3 to $30 \mathrm{~cm}^{2}$ and increased lunar illumination fraction (LIF) from 0 to $25 \%$. Presented values are model-averaged predictions with $95 \%$ prediction intervals shown in brackets. Behavior predictions for changes in CFSA and LIF were produced using model-averaged estimates and median values for all other factors during 2007

\begin{tabular}{|c|c|c|c|c|c|c|}
\hline \multirow{2}{*}{ Behavior } & \multicolumn{2}{|c|}{ cFSA } & \multirow{2}{*}{$\begin{array}{c}\text { Change } \\
(\%)\end{array}$} & \multicolumn{2}{|c|}{ LIF } & \multirow{2}{*}{$\begin{array}{c}\text { Change } \\
(\%)\end{array}$} \\
\hline & $3 \mathrm{~cm}^{2}$ & $30 \mathrm{~cm}^{2}$ & & $0 \%$ & $25 \%$ & \\
\hline Dive duration (s) & $\begin{array}{c}23.1 \\
{[21.2,25.2]}\end{array}$ & $\begin{array}{c}21.6 \\
{[20.4,22.8]}\end{array}$ & -6 & $\begin{array}{c}24.3 \\
{[23.0,25.7]}\end{array}$ & $\begin{array}{c}45.7 \\
{[42.1,49.5]}\end{array}$ & 88 \\
\hline Descent rate $\left(\mathrm{m} \mathrm{s}^{-1}\right)$ & $\begin{array}{c}0.91 \\
{[0.83,1.01]}\end{array}$ & $\begin{array}{c}0.99 \\
{[0.94,1.05]}\end{array}$ & 9 & $\begin{array}{c}1.02 \\
{[0.96,1.07]}\end{array}$ & $\begin{array}{c}0.90 \\
{[0.83,0.96]}\end{array}$ & -12 \\
\hline Ascent rate $\left(\mathrm{m} \mathrm{s}^{-1}\right)$ & $\begin{array}{c}0.84 \\
{[0.75,0.92]}\end{array}$ & $\begin{array}{c}0.97 \\
{[0.91,1.02]}\end{array}$ & 15 & & & \\
\hline
\end{tabular}


the strongest predictor of behavior in terms of the number of behaviors it affected and magnitude of its effects. Most prominently, females dove deeper during periods of high nighttime moonlight. Similar to reports at other portions of the species' range, vertically migrating prey species appear to make up a substantial portion of female northern fur seal diet on Lovushki (Waite et al. 2012). Therefore, the simplest explanation for this effect was that females were tracking changes in the distribution of their prey (Croxall et al. 1985, Horning \& Trillmich 1999, Ream et al. 2005, Lea et al. 2010). Beyond what was predicted as a result of increased foraging depths, females also extended their dive durations during periods of greater moonlight. This may have been due, in part, to females making adjustments during different phases of their dives because bottom times were longer and descent and ascent rates were slower during these periods. Furthermore, increased moonlight caused Lovushki females to modify their behavior at broader scales as indicated by lower dive rates and shorter bout durations. These measures can be considered indices of foraging effort (Costa 1988, Boyd \& Croxall 1992, Boyd et al. 1994). Although it is unknown if Lovushki seals were experiencing reduced prey availability with increased moonlight, female Galápagos fur seals Arctocephalus galapagoensis experienced mass loss during full moon periods (Horning \& Trillmich 1999). Furthermore, decreased prey availability may explain why Lovushki females increased their foraging trip durations during periods of higher moonlight. They may have required additional foraging time to compensate for periods when prey were difficult or impossible to access. Ambient light may not affect all females in the same manner, however, because attributes of certain individuals may make them better equipped to deal with these changes in prey distribution.

\section{Female size effects}

One of the most studied determinants of dive ability for marine mammals is body size (Kooyman 1989). The diving capabilities of first-year northern fur seal pups were found to be correlated with their body size (Lea et al. 2010). Among Galápagos fur seals, size may have partly explained differences in mean dive depth between adult females and juvenile seals (Horning \& Trillmich 1999). However, for adult female northern fur seals on Lovushki, with sizes ranging from 28.7 to $58.9 \mathrm{~kg}$, we found no relationship between diving behaviors and size. This may be because they typically made dives that were 1-2 min shorter than their calculated aerobic dive limit (CADL) of $2.6 \mathrm{~min}$ (Shero et al. 2012). Size may only influence female fur seal behavior when they are forced to dive at or near their physiological limits (Costa et al. 2001, Staniland et al. 2010). Two other results indicated that female size did influence individual foraging effort. First, larger females spent less time onshore without changing the amount of time they spent foraging at sea. Over the course of the lactation period, this strategy may have allowed larger females to invest a greater amount of time foraging. Second, larger females spent a higher proportion of time at sea diving while at sea compared to smaller females. They apparently accomplished this by lengthening their foraging bouts at the expense of resting between bouts. Assuming that it is advantageous for females to maximize foraging time while at sea, these results may suggest that smaller females are physiologically limited compared to larger females. Although in this study female northern fur seals typically made dives less than their cADL, $\mathrm{CO}_{2}$ may accumulate during normal, sequential dives and therefore influence the ending of dive bouts. Larger females with lower mass-specific metabolic rates may be able to conduct more dives before needing to rest. Additionally, larger seals may have a larger stomach capacity, which may permit them to forage longer before needing to stop for digestion. Furthermore, differences caused by female age should not be ruled out because on the Pribilof Islands, older, larger female northern fur seals dive deeper and make shorter foraging trips than younger, smaller females (Goebel 1988). Future work should consider examining proxies for ingestion rates (e.g. wiggles or even more direct measures such as head striking) to determine if food intake is limited for smaller females. Beyond effects caused by intrinsic differences between individuals, study methods, such as those that change hydrodynamic characteristics, may also influence individual behavior.

\section{Instrumentation effects}

We found that animal-borne instruments affected the fine-scale foraging behavior of Lovushki females. In Table 6, we present model predictions that compare the effects of a very small instrument package ( $\mathrm{CFSA}=3 \mathrm{~cm}^{2}$ ) to those of a medium-sized package $\left(\right.$ CFSA $\left.=30 \mathrm{~cm}^{2}\right)$. A seal with the medium-sized instrument would experience a $6 \%$ decrease in dive duration and 9 and $15 \%$ increases in descent and 
ascent rates, respectively. Instrument effects have been reported in several previous fur seal studies (Boyd et al. 1991, 1997, Walker \& Boveng 1995, McCafferty et al. 1998). Boyd et al. (1997) performed an experiment by gluing a wood block of cFSA = $21.15 \mathrm{~cm}^{2}$ to a treatment group of lactating Antarctic fur seals. With increased drag, Antarctic fur seals significantly decreased their dive duration but, contrary to our findings, may have decreased their mean descent and ascent rates, although not significantly so. Differences may be related to how females of these 2 species changed their dive angle in relation to swim speed with increased drag.

We further examined whether our observed increases in ascent and descent rates in response to increased cFSA were reasonable given previously reported instrument effects. Antarctic fur seals change both their swim speed and dive angles with increased drag (Boyd et al. 1997). In that study, seals with added drag showed a reduction in swim speed from 1.23 to $0.98 \mathrm{~m} \mathrm{~s}^{-1}$ and an increase in dive angles by as much as $40^{\circ}$ compared to seals without added drag. Using these values, we calculated that even after considering a similar slowing of swim speed, our predicted $9 \%$ increase in descent rate with the attachment of medium-sized instruments (cFSA $=30$ $\mathrm{cm}^{2}$; see Table 6) could have been explained by females changing their dive descent angles from 45 to $80^{\circ}$ below horizontal. We therefore suggest that the increases in female ascent and descent rates in response to larger instrument $\mathrm{cFSA}$ on Lovushki could be explained by females choosing to reduce the distance they traveled (i.e. steepening dive angles) and energy they expended (i.e. lowering swim speeds) while traveling to foraging depths. If our assumptions were correct, females may have been making nearly vertical dives with the attachment of medium-sized instruments and, therefore, ascent and descent rates may have to decrease with instruments of even larger size. This may explain why ascent rates decreased for female Antarctic fur seals when a video camera with a frontal surface area of $46.75 \mathrm{~cm}^{2}$ was used to study their behavior (Heaslip \& Hooker 2008).

Broad-scale foraging behaviors, such as dive rate, bout length, proportion of time at sea spent diving, and foraging trip duration, were not significantly affected by instrument size in this study. This result was surprising given that animal-borne instruments cause an apparent increase in foraging metabolic costs for lactating northern fur seals (Costa \& Gentry 1986). With instrument attachment, Antarctic fur seals respond to these costs by increasing foraging trip dura- tion by 15 to $30 \%$ (in Walker \& Boveng 1995 and Boyd et al. 1997, respectively), while northern fur seals in other studies responded by increasing their proportion of time at sea spent diving with no change in foraging trip duration (Costa et al. 1989). Furthermore, the mass change rates we observed did not vary with instrument CFSA. It therefore seems that Lovushki females were capable of compensating for additional instrument-related costs, possibly by making changes to dive angles and potentially other behaviors we did not examine (e.g. travel path tortuosity).

Although quantifying instrument effects is important for interpreting results when studying behavior, it is also a practice of good ethics (McMahon et al. 2011, Vandenabeele et al. 2011). For several reasons, we suggest that the drag effects caused by the attachment of medium-sized instruments caused minimal biological impact to lactating northern fur seals on Lovushki. First, relatively few fine-scale behaviors were affected by instrument drag, and the magnitudes of those effects were unexceptional. Changes in lunar illuminance equivalent to that caused by the moon waxing from new to first-quarter phase changed female dive duration by $88 \%$ and descent rate by $9 \%$, while attachment of a mediumsized instrument caused a 6 and $12 \%$ change in dive duration and descent rate, respectively (Table 6). Secondly, mass change rates appeared unaffected by the range of instrument sizes we used in this study. Females appeared to be able to compensate for increased transport costs by making minor changes to their behavior. Finally, females did not need to compensate for instrument effects by adjusting their foraging trip durations or shore visits. Changes to the foraging cycle can have a detrimental effect on pup development and, if possible, are generally avoided by lactating seals (Costa 2007). In contrast, Lovushki females did have to increase foraging trip duration during periods of greater moonlight. Although we suggest that instruments had a relatively small impact on females here, these findings should not be generalized beyond the current study because differences in prey, habitat, or environmental conditions may constrain individual behavior differently across time and space.

\section{Future studies}

Although the influential factors we presented here were not exhaustive, they do offer a starting point for designing future northern fur seal comparative studies. First, our findings reemphasize that population- 
wide estimates of northern fur seal behaviors can be biased if sampling methods are used that do not adequately represent the entire range of behaviors within the population. This may include capture techniques that favor animals of a certain age or size. Biases may also result when examining behavior over short periods of time that reflect transient conditions, such as part of a lunar cycle, but not long-term processes that are more likely to influence the population on a longer scale. Therefore, observations should ideally be collected over the entire period of lactation on individuals representing the greater population. Second, even when behavior is adequately represented, localized factors influencing individual behavior must still be considered when comparing behavior across populations or over different time periods. Modeling the influences of localized factors (e.g. weather, moonlight, bathymetry) may not only provide insights about the mechanisms driving behavior but may also allow better interpretation of results from natural experiments. For example, we have shown here that failing to consider moonlight in a study reporting instrument effects could lead to erroneous conclusions. Third, models should account for differences in the degree to which factors influence seal behavior across geographic populations (e.g. include a 'seal size*location' term) because these interactions may provide information about behavioral plasticity within the species. For example, female Antarctic fur seal mass influences behavior differently across sites with contrasting environments (Staniland et al. 2010). A similar comparison for northern fur seals may improve our understanding about how habitat differentially constrains the populations on Lovushki and the Pribilof Islands. Finally, future studies should examine how these factors influence nursing pups. Although none of the factors we examined were found to affect female mass change rates, moonlight potentially influenced pup development because females extended their foraging trips during periods of greater moonlight. Measurements of pup development and survival across different conditions would provide a better understanding of how intrinsic and extrinsic factors that influence female behavior ultimately affect their reproductive success, and, therefore, populationscale trends.

\section{CONCLUSIONS}

Although the foraging behavior of Lovushki females seemed to indicate that they were investing less effort in finding food compared to females on the Pribilof Islands, our findings suggest that many factors, some of which may not relate to prey availability, can strongly influence individual behavior and therefore should be considered. In particular, individual behavior differs with respect to several factors including body size, ambient light, and size of attached instruments. Accounting for these factors may not only be essential for developing unbiased estimates for foraging behavior but may also offer insights into the mechanisms behind differences in population foraging effort. With consideration given to factors we presented here, a fine-scale comparison of lactating seal behavior on the Pribilof and Lovushki Islands may provide an opportunity to study whether food limitations are contributing to declines of Pribilof northern fur seal populations.

Acknowledgements. We thank K. Abernathy, D. Webb, V. Aderholt, A. V Altukhov, R. V. Belobrov, V. A. Burkanova, N. N. Kutrukhin, D. Calkins, D. Holley, E. G. Mamaev, Y. Mitani, S. N. Norberg, D. S. Pasenyuk, P. A. Permyakov, S. Y. Purtov, O. V. Savenko, S. N. Sergeev, T. S. Shulezhko, A. A. Sychenko, A. V. Tret'yakov, and J. N. Waite. Funding was provided by the National Oceanic and Atmospheric Administration via grants to the Alaska SeaLife Center and the National Marine Mammal Laboratory, with additional funding and logistical support from North Pacific Wildlife Consulting. This work was authorized by the Alaska SeaLife Center Institutional Animal Care and Use Committee and conducted under permits from the following Russian permitting agencies: the Sakhalin Department of the Federal Fisheries Agency of Russia (Sakhalinrybvod), the Federal Veterinary and Agricultural Control Service (Rosselkhoznadzor, Sakhalin Region), and the Sakhalin-Kuril Territorial Department of the Federal Committee of Fisheries of Russia (Goskomrybolovstvo).

\section{LITERATURE CITED}

Arnould JPY, Hindell MA (2001) Dive behaviour, foraging locations, and maternal-attendance patterns of Australian fur seals (Arctocephalus pusillus doriferus). Can J Zool 79:35-48

Arnould JPY, Boyd IL, Speakman JR (1996) The relationship between foraging behaviour and energy expenditure in Antarctic fur seals. J Zool 239:769-782

Austin RH, Phillips BF, Webb DJ (1976) A method for calculating moonlight illuminance at the earth's surface. J Appl Ecol 13:741-748

Beauplet G, Dubroca L, Guinet C, Cherel Y, Dabin W, Gagne C, Hindell M (2004) Foraging ecology of subantarctic fur seals Arctocephalus tropicalis breeding on Amsterdam Island: seasonal changes in relation to maternal characteristics and pup growth. Mar Ecol Prog Ser 273:211-225

Boden BP, Kampa EM (1967) The influence of natural light on the vertical migrations of an animal community in the sea. Symp Zool Soc Lond 19:15-26 
Boyd IL, Croxall JP (1992) Diving behaviour of lactating Antarctic fur seals. Can J Zool 70:919-928

Boyd IL, Lunn NJ, Barton T (1991) Time budgets and foraging characteristics of lactating Antarctic fur seals. J Anim Ecol 60:577-592

Boyd IL, Arnould JPY, Barton T, Croxall JP (1994) Foraging behaviour of Antarctic fur seals during periods of contrasting prey abundance. J Anim Ecol 63:703-713

Boyd IL, McCafferty DJ, Walker TR (1997) Variation in foraging effort by lactating Antarctic fur seals: response to simulated increased foraging costs. Behav Ecol Sociobiol 40:135-144

Burkanov VN, Andrews RD, Calkins DG, Waite JN (2007) Northern fur seal (Callorhinus ursinus) pup production in the Kuril Islands, 2005-2006. Alaska Marine Science Symposium. January 2007. Anchorage, AK

Burnham KP, Anderson DR (eds) (2002) Model selection and multimodel inference: a practical information-theoretic approach. Springer-Verlag, New York, NY

> Call KA, Ream RR, Johnson D, Sterling JT, Towell RG (2008) Foraging route tactics and site fidelity of adult female northern fur seal (Callorhinus ursinus) around the Pribilof Islands. Deep-Sea Res II 55:1883-1896

Costa DP (1988) Methods for studying the energetics of freely diving animals. Can J Zool 66:45-52

Costa DP (2007) A conceptual model of the variation in parental attendance in response to environmental fluctuation: foraging energetics of lactating sea lions and fur seals. Aquat Conserv: Mar Freshw Ecosyst 17:S44-S52

Costa DP, Gentry RL (1986) Reproductive energetics of the northern fur seal. In: Gentry RL, Kooyman GL (eds) Fur seals: maternal strategies on land and at sea. Princeton University Press, Princeton, NJ, p 79-101

Costa DP, Croxall JP, Duck CD (1989) Foraging energetics of Antarctic fur seals in relation to changes in prey availability. Ecology 70:596-606

Costa DP, Gales NJ, Goebel ME (2001) Aerobic dive limit: How often does it occur in nature? Comp Biochem Physiol A 129:771-783

Croxall JP, Everson I, Kooyman GL, Ricketts C, Davis RW (1985) Fur seal diving behaviour in relation to vertical distribution of krill. J Anim Ecol 54:1-8

Gentry RL (1998) Female attendance behaviour. In: Gentry RL (ed) Behavior and ecology of the northern fur seal. Princeton University Press, Princeton, NJ, p 219-231

Gentry RL, Holt JR (1986) Attendance behavior of northern fur seals. In: Gentry RL, Kooyman GL (eds) Fur seals: material strategies on land and at sea. Princeton University Press, Princeton, NJ, p 41-68

Gentry RL, Kooyman GL, Goebel ME (1986) Feeding and diving behavior of northern fur seals. In: Gentry RL, Kooyman GL (eds) Fur seals: maternal strategies on land and at sea. Princeton University Press, Princeton, NJ, p 61-78

Goebel ME (1988) Duration of feeding trips and age-related reproductive success of lactating females, St. Paul Island, Alaska. In: Kozloff P, Kajimura H (eds) Fur seal investigations, 1985. NOAA Tech Memo NMFS F/NWC-146: 28-33

Goebel ME, Bengtson JL, DeLong RL, Gentry RL, Loughlin TR (1991) Diving patterns and foraging locations of female northern fur seals. Fish Bull 89:171-179

Goldsworthy SD (1999) Maternal attendance behaviour of sympatrically breeding Antarctic and subantarctic fur seals, Arctocephalus spp., at Macquarie Island. Polar Biol

\section{1:316-325}

> Heaslip SG, Hooker SK (2008) Effect of animal-borne camera and flash on the diving behaviour of the female Antarctic fur seal (Arctocephalus gazella). Deep-Sea Res I 55:1179-1192

Heath RB, Calkins D, McAllister D, Taylor W, Spraker T (1996) Telazol and isoflurane field anesthesia in freeranging Steller's sea lions (Eumetopias jubatus). J Zoo Wildl Med 27:35-43

$>$ Horning M, Trillmich F (1999) Lunar cycles in diel prey migrations exert a stronger effect on the diving of juveniles than adult Galápagos fur seals. Proc R Soc Lond B Biol Sci 266:1127-1132

Houston AI, Carbone C (1992) The optimal allocation of time during the diving cycle. Behav Ecol 3:255-265

Kooyman GL (1989) Diverse divers: physiology and behavior. Springer-Verlag, Berlin

Kuhn CE (2010) The influence of subsurface thermal structure on the diving behavior of northern fur seals (Callorhinus ursinus) during the breeding season. Mar Biol 158:649-663

> Lea MA, Johnson D, Melin S, Ream R, Gelatt T (2010) Diving ontogeny and lunar responses in a highly migratory mammal, the northern fur seal Callorhinus ursinus. Mar Ecol Prog Ser 419:233-247

Loughlin TR, Bengtson JL, Merrick RL (1987) Characteristics of feeding trips of female northern fur seals. Can J Zool 65:2079-2084

Luque SP (2007) Diving behaviour analysis in R. R News 7 : 8-14

Mazerolle MJ (2011) AICcmodavg: model selection and multimodel inference based on (Q)AIC(c). R package version 1.17. Available at http://cran.r-project.org/web/ packages/AICcmodavg/

McCafferty DJ, Boyd IL, Walker TR, Taylor RI (1998) Foraging responses of Antarctic fur seals to changes in the marine environment. Mar Ecol Prog Ser 166:285-299

McCullagh P, Nelder JA (1989) Generalized linear models, 2nd edn. Chapman \& Hall, London

McDonald BI, Goebel ME, Crocker DE, Tremblay Y, Costa DP (2009) Effects of maternal traits and individual behavior on the foraging strategies and provisioning rates of an income breeder, the Antarctic fur seal. Mar Ecol Prog Ser 394:277-288

McMahon C, Collier N, Northfield JK, Glen F (2011) Taking the time to assess the effects of remote sensing and tracking devices on animals. Anim Welf 20:515-521

National Marine Fisheries Service (2007) Conservation plan for the eastern Pacific stock of northern fur seal (Callorhinus ursinus). NMFS, Juneau, AK

Pinheiro J, Bates D, DebRoy S, Sarkar D (2011) nlme: linear and nonlinear mixed effects models. R package version 3.1-96. Available at http://cran.r-project.org/web/ packages/nlme

R Development Core Team (2010) R: a language and environment for statistical computing. R Foundation for Statistical Computing, Vienna. Available at www.R-project. org

Ream RR, Baker JD, Towell RG (1999) Bogoslof Island studies, 1997. In: Sinclair EH, Robson BW (eds) Fur seal investigations, 1997. NOAA Tech Memo NMFS AFSC106:81-104

Ream RR, Sterling JT, Loughlin TR (2005) Oceanographic features related to northern fur seal migratory movements. Deep-Sea Res II 52:823-843 
Schreer JF, Kovacs KM (1997) Allometry of diving capacity in air-breathing vertebrates. Can J Zool 75:339-358

Shero MR, Andrews RD, Lestyk KC, Burns JM (2012) Development of the aerobic dive limit and muscular efficiency in northern fur seals (Callorhinus ursinus). J Comp Physiol B 182:425-436

Sibly RM, Nott HMR, Fletcher DJ (1990) Splitting behaviour into bouts. Anim Behav 39:63-69

Sinclair EH, Loughlin TR, Pearcy W (1994) Prey selection by northern fur seals (Callorhinus ursinus) in the eastern Bering Sea. Fish Bull 92:144-156

Staniland I, Gales N, Warren N, Robinson S, Goldsworthy S, Casper R (2010) Geographical variation in the behaviour of a central place forager: Antarctic fur seals foraging in contrasting environments. Mar Biol 157: 2383-2396

Sterling JT (2009) Northern fur seal foraging behaviors, food webs, and interactions with oceanographic features in

Editorial responsibility: Rory Wilson,

Swansea, UK the eastern Bering Sea. PhD dissertation, University of Washington, Seattle, WA

Towell RG, Ream RR, York AE (2006) Decline in northern fur seal (Callorhinus ursinus) pup production on the Pribilof Islands. Mar Mamm Sci 22:486-491

Trillmich F (1990) The behavioral ecology of maternal effort in fur seals and sea lions. Behaviour 114:3-20

Vandenabeele SP, Wilson RP, Grogan A (2011) Tags on seabirds: How seriously are instrument-induced behaviours considered? Anim Welf 20:559-571

Waite JN, Burkanov VN, Andrews RD (2012) Prey competition between sympatric Steller sea lions (Eumetopias jubatus) and northern fur seals (Callorhinus ursinus) on Lovushki Island, Russia. Can J Zool 90:110-127

> Walker BG, Boveng PL (1995) Effects of time-depth recorders on maternal foraging and attendance behavior of Antarctic fur seals (Arctocephalus gazella). Can J Zool 73:1538-1544

Submitted: March 21, 2012; Accepted: September 3, 2012 Proofs received from author(s): December 3, 2012 